\title{
Mobility in Urban Social Events: \\ Towards Organizational Transvergence
}

\begin{abstract}
The paper explores the emergence of territories that are constituted through spontaneous assembling of self-organized communities resulting in what we term, urban social events. A concrete event is employed namely Embros, an open occupation of an abandoned public building in the center of Athens, to highlight the dynamics that make urban social events transformative urban phenomena. By focusing upon the entangled mobilities of diverse agents, we explain how through differential, dis-continual assembling and creative collaborations, such urban social interactions institute unbounded and immanent modes of organizing. The paper contributes to organizational territoriality studies (OTS) proposing that urban social events are mobile entanglements that institute practices of creative trans-actions with formal or informal communities. By doing that, it places the Arts, creativity and community participation at the centre of transformative organizing.
\end{abstract}

Keywords: Assembling, Territories, Transvergence, Urban. 


\section{Introduction}

Geography has been traditionally equated with fixity and stasis. Nevertheless, in 19th Century Europe, discourses of liberty and progress were discussed in relation to the ability to move (Sennett 1994). By the 20th Century, new subject positions were constructed with the emerging identity of the tourist, the vagabond, globetrotter and the hobo. Gradually, poststructuralist (e.g. Gibson-Graham 1997; Doel 1999; Murdoch 2006), non-representational and relational approaches (Massey 2005; Cresswell 2006; Thrift 2008) developed relational readings of the urban environment and highlighted the concepts of movement and moving space. In particular, relational views suggest that mobile space is context specific and can only be described in terms of irregularity, unexpected or changing dimensions (Thrift 2008).

One of the most important contributions in the relational place literature is Massey's (2005) who re-conceptualizes isolated and bounded place identities to propose internally multiple places that include 'fractures and ruptures' (p.100) that is, open spaces in which individuals have to do something of them even temporarily. This temporary inhabitation changes space, highlighting more a process of negotiation rather than rootedness, of practice of becoming rather than being. Upon this 'critical relational geographies' tradition (Thirft 1996; Amin and Thirft 2002, Massey 2005; Jensen 2009) we build, in our study of collective and emergent urban social events and their association with new terrains for organizing social relations.

Challenging both inquiries and methodologies for research in the study of culture and organizations which has largely remained 'a-mobile', we problematize sedentary approaches to organizing that treat organizations as fixed dwellings or fixed 
geographical containers for social processes. We go beyond disciplinary boundaries and explore social urban life as a phenomenon of multiple and extended connections, organized through certain nodes or places of intermittent movement; these constitute corridors of organizing with complex intersections of 'endless regimes of flow', which move at different 'speeds', 'scales' and 'viscosities' (Lassen 2006; Law 2006). As proposed in a recent Special Issue (Culture and Organization, 2013) on organizational territoriality studies (OTS) and territorial organization (Maréchal et al. 2013), mobility is a crucial component of contemporary organizational experiences and co-institutes complex modes of social engagement.

In thinking of such modes, we identify the assemblages and practices that are brought into play in and through collaborative urban social processes. Assemblage 'designates the actualizations of the virtual causes or causal processes that are immanent in an open system of intensities that is under the influence of a force that is external (or heterogeneous) in relation to it' (Markus and Saka 2006, 103) ${ }^{1}$. Urban social events therefore are seen here as collaborative environments of organizing that engage interested constituencies in and through particular urban sites or 'trans-spaces'; these are intersecting places that 'make new and often interscalar connections between different and sometimes unlikely, groups of people, institutions, and paradigms' (Mar and Anderson 2012, 340). By focusing on the practices of an urban social event of differential circulations intersecting with the same locale, we illustrate the dynamic of mobilities in the making of what we call, transvergent sites of organizing.

\footnotetext{
${ }^{1}$ For an extensive discussion on assemblages, literature includes Deleuze and Guattari, 1987; Latour, 2005; DeLanda 2006, McCann 2011 and McFarlane 2001.
} 
Transvergent organizing ${ }^{2}$ requires 'a multidimensional continuum from inner to outer space, from the naturally inanimate to the artificially inanimate, from virtuality to actuality, from every sensory modality to every other, and from action to reaction to interaction to eventual transaction (defined here as interaction leading to mutual transformation or change' (Novak 2004). In the field of organizational analysis, the concept of transvergence has been mentioned only in relation to globalization and was defined a 'transformative reinterpretation of practice' (Gupta and Wang 2004, 37). Expanding this concept of transformative re-interpretation and applying it in a different context here, we propose that such a process requires de-territorialization, territorialization and re-territorialization of practices achieved through entering and exiting organizational forms (multiple belongings) and translocal presence (temporary emplacements).

Unquestionably, transformation tactics are linked to complex interfaces including institutions, commercial partners, and other public and private organizations. Our focus here, however, is not the power relations among entities and the political issues emanating from the process of transformation but, consistent with assemblage analytics, the description of the assemblages that emerge in the trans-spaces of these urban social projects and their dynamics of organizing. We propose that urban social events incorporate the fixity/mobility dialectic, constructing temporary zones of engagement through entangled mobilities; movement of people and materials across and between spaces constitutes the social and its spatial expression.

Hence, we explore social relationships during urban events as dense mobility

\footnotetext{
${ }^{2}$ From Marcos Novak term 'transvergence' (1992, 1999, 2001).
} 
assemblages. These sociomaterialities, through moving across social contexts of interaction, trace new often ignored potentialities. The first part of the paper discusses urban social events as a process of transformative assembling. Then the case of Embros, the metamorphosis of an abandoned building in the center of Athens is discussed, describing the dynamics that make it a transformative urban phenomenon. Due to the fact that Embros constitutes a creative resistance event that assembles multitudes of intersecting subjectivities, it becomes an ideal place to commence the study of transvergent organizational processes. These processes, the paper concludes, institute practices of creative trans-actions with formal or informal communities, which are actively looking to establish an alternative that puts the arts, creativity, difference and community engagement at the centre of organizing social and cultural spaces.

\section{Mobilities as Urban Social Events}

Spaces of mobility are not soulless non-places (Auge 1995) but lived places, sites of culturally significant practice. The moving urbanite engages with multiple (electronic) agoras, linked in movement: 'mobility is a movement that produces cultures' (Jensen 2009,154). Organizations can be explored as mobility environments, which constitute dynamic practices of alignment and dis-alignment capitalizing on the co-presence of people in the same territory on a temporary basis. During this temporary fixity of material worlds, mobilizations of locality are performed and re-assembling of place is materialized. Based on this, 'places do not make for a good starting point, since every one of them are framed and localized by others . . Circulation is first, the landscape "in which" templates and agents of all sorts and colors circulate is second' (Latour 2005, 196). We pursue this point of circulation therefore, and reflect upon 
movements, which constitute particular collaborative partnerships and alternative organizing arenas.

The majority of the existing literature on urban social events, reinforcing dualism in urban cultural relations, discusses them as crystallized resistance practices, distinctive urban subcultures in opposition to the dominant urban process (see for example, skateboarding; Borden 2001, Parkour; Daskalaki et al. 2008; Mould 2009; Urban Exploration; Garrett 2010). Nevertheless, 'by entering the public space one risks encounter with those who are different, those who identify with different groups and have different opinions or different forms of life' (Young 1990, 240); public space is an open place (Weintraub 1995; Ruppert 2006) accessible to diverse social groupings or formations.

Urban formations become part of a movement, a process of transformation that redefines subcultures as evolving social formations through a process of continuous assembling. The effects of these practices do not only subvert and global urban regimes; Urban social events can also become collective, fertile, engaging and transformative territories that assemble both organized communities and mobile (disperse, disparate and transient) agents such as freelancers, academics, activists, neighborhood residents or artists. Following this, an inquiry into the nature of urban social events, not exclusively as political or cultural activism but as productive engagements of a transformative potential is fundamental.

Urban social events are social intersections that give communities a mode of participation and engagement in a public space. Their temporary subjectivities are 
performed as explorations of the urban unknown and unseen and at the same time, are a product of inhabiting a city of possibility, performative rediscovery and improvisation. Urban social events are an invitation to the other, in that the "intraaction' (Barad, 2001; 2007) that they entail (other voices, other uses space or other paths) becomes another way to connect and thus transform. Intra-action involves temporary territorializations that remain, however, in an immanent state of becoming (DeLanda, 2006), introducing, interrupting, erupting, cultivating, maintaining, reactivating, inventing and transgressing events and relationships; this process allows for the unimaginable, invisible and, what Bloch (1986) and Deleuze and Guattari (1987) called, 'yet to come'

Nevertheless, mobilities cannot be described without spatial, infrastructural and institutional moorings, which by creating a spatial fix (Harvey 1989) enable movement. Movement, in turn, only becomes meaningful because encounters in engaging places can cause stillness. Place is a spectrum of continuous performance, an event, rather than a juxtaposition of dualist divisions (see Massey 2007; Harvey 2009). Transient subjectivities are constantly constructed as part of a cyclical relationship between all lived elements of the human condition:

'Mobility without meaning and significance is simply movement, an abstraction from point-to-point. We see mobility not in terms of consumption, but in terms of production; how movement is given meaning in economic, social, cultural contexts -which can become ideologically bound to place' (Adey and Bevan 2004, II).

Assemblages, according to that, become de-territorialized and re-territorialized, mobile in search of new modes of expression and transformative belonging through inhabitation/creation of new territories; moorings are as important as mobilities (Cresswell 2006). Movement can only be interrupted temporarily while engaging with 
territories during assembling. Following this, mobility is a property of moving bodies that participate in multiple assembling processes, occupying trans-identities and engaging in meaningful and transformative social relations. The following section defines and discusses the concept of transvergence, in the context of a concrete event, Embros. This event reflects assemblages' immanence and capacity for intriguing heterogeneous engagement and relational creativity.

\section{Embros: Towards a Transvergent Environment for Organizing}

Public protests, guerrilla gardening, public cafes and other (activist/virtual) networks are examples of urban social events characterized by inherent mobility. Urban social events constitute a process of assembling evental sites (Badiou 2005); it is their mobile character, their fragility (Badiou 2005) that produces engaging places in which creative participative interactions transform the urban experience towards the unforeseen and the unknown. Embros (see Figure 1), the occupation of an abandoned public building in Athens (Greece) by residents groups and members of the public, is a social event that illustrates the role of informal, self-organized communities as a force of social transformation.

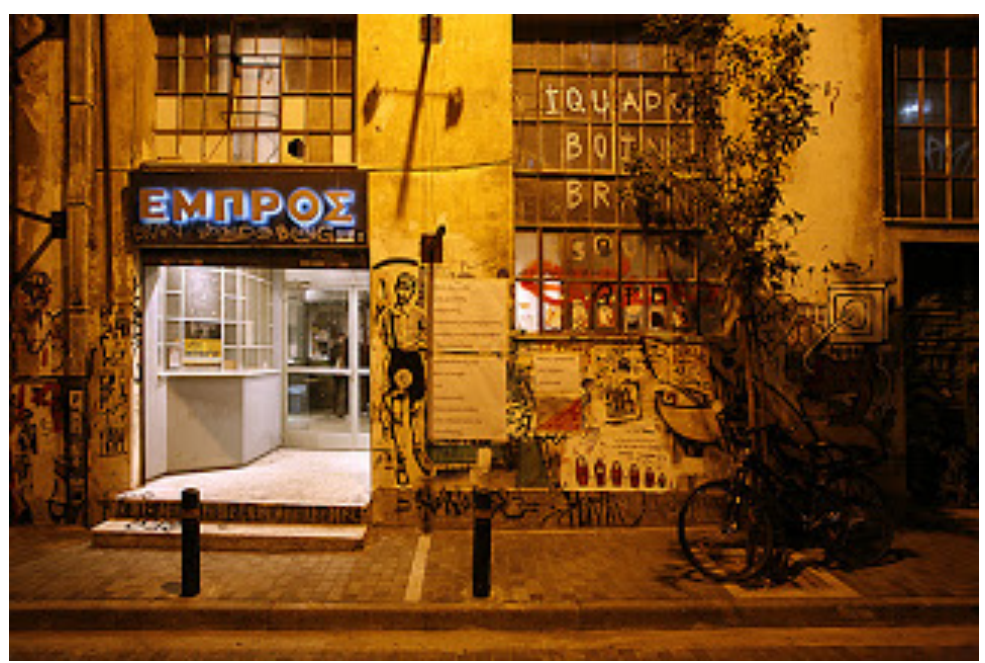

Figure 1: The entrance of Embros 
Most of the insights in this paper come from participant observations of the unfolding process as well as a digital ethnographic work where posts on the web from various participating collectives have been followed, collected and analyzed. Embros' virtual presence is broad and consistent and it largely relies on blog announcements from various collectives (Mavili Collective; Kollectiva Omonia) to maintain flow of information as well as promote the practices and discussions undertaken before, during and after the events. In addition, several residents' and workers' movements (Psirri Residents and Workers Movement), which have actively been involved with the establishment and transformation of the site, offer their support and solidarity through blogs and virtual statements. Following Embros-related blogs (receiving an email with the material posted on the relevant websites) provided a rich pool of publications that included both information about the participants' official views and proposals as well as others' reactions and related activities. This digital material allowed for a longitudinal examination of a process that describes the emergence and evolution of Embros as an urban social event.

It was considered important to analyze these blogs in conjunction with a series of minutes from the Open Assemblies and unstructured interviews that we had with event participants. Open Assemblies are normally attended by anyone interested in joining in and minutes from these meetings are distributed to everyone who registers at the blogs and follows Embros' activities. Decision-making about future action is consensual and the participants who visit and stay at Embros on an everyday basis follow up all action points. For this paper, we observed five monthly assemblies and collected published minutes from them including one 'opening statement', the 
Embros Manifesto (11 ${ }^{\text {th }}$ of November 2011).

The Manifesto managed to mobilize communities all over Athens to participate, occupy and transform the abandoned public building into a space of creative, socialcultural engagement. These communities predominantly included artists, creatives and academics, yet other informal and formal collectivities and activist groups also joined. Increasingly, other occupied spaces, co-operatives and students' organizations got actively involved participating either as organizers, performers or discussants. A cultural/creative social movement (the Mavili Collective) declared:

'We aim to re-activate this space temporarily with our own means and propose an alternative model of collective management and post-contemporary forms of creative work...This re-activation is not a proposition of a "better" model of production and management but is a proposition of re-thinking, responding and re-making. This model emerges from the current lacks and shortfalls of our system and attempts to interrogate the global changing landscape at this moment in time. We challenge our own limits and understanding and we propose and operate this space as a constantly re-evaluated model by both ourselves and the public - an open system that might offer the potential to re-think relations between people and possible roles for art in society' (Mavili Collective, theatreworld.wordpress.com).

The Greek government reacted: though it demanded the evacuation of Embros soon after its open occupation, it failed in successfully evicting the collective, which gathered invariably in the building and protected the rights of the occupants to engage in public activities in a free public place:

'In the sight of the current situation we refuse to wait for "better days", we refuse to accept the current crisis as terminal and we refuse to sit back. We actively propose new structures, which we hope, can become sites of negotiation, debate, re-formulation' (Mavili Collective, theatreworld.wordpress.com).

Being unable to financially support cultural practices or to create new social structures in response to the current crisis, the state failed persuading the people that events like the re-inhabitation of Embros are not desirable for the support and engagement of diverse, dispersed and misplaced local cultures. The group promotes this engagement through the

're-activation of an uninhibited space that brings together artists, theoreticians, dance/theatre makers, 
architects and the general public through the organization of free gatherings. The occupation reconstitutes Embros as a public space for exchange, research, and debate' (Mavili Collective, theatreworld.wordpress.com).

The local residents and people who work in the area assemble at a concrete place temporarily folding and unfolding relationships demonstrating the power of collaborative participation in changing things that once may have been considered stable. They have openly stated their support:

'For the recovery of public space, to eliminate the fear, discrimination, ignorance and suspicion. To stop the violation of the historic center of the city from all sorts of selfish interests. To do any more understandable to all that the city model of entertainment has ended, leaving behind ruins and open wounds in the urban fabric. To get the neighborhood and city in our hands, promoting the idea of creation and management of commons, relating not only to the residents and workers of Psiri (the neighborhood) but throughout Athens. To enable the city to reside the difference. Why the crisis requires action, solidarity, self-organization and seeking alternative lifestyles among residents, permanent and temporary, regardless of gender, race and origin' (Psirri Residents and Workers Movement).

In September 2013, the Greek government, closing the site again, included Embros into the Hellenic Republic Asset Development Fund's (HRADF), the fund of public assets on sale, which is under the Troika control. This has taken control from the Ministry of Culture and the local government bodies and passed Embros management to the Ministry of Finance, currently run under the direction of the Troika. The site was sealed - the usual reaction of the Greek police against occupations- yet this time, private security was placed in front of the building in a 24-hour surveillance. The state declared that they intend to sell the building privately for an as yet unspecified use. One participant, in the Open Assembly outside the sealed theatre, stated:

There is a group of lawyers that could help citizens to appeal to court for this (including Embros HRDF)... beyond that however, in practical terms, what can we do now? We have legal consequences if we decide to re-enter the theatre; besides what will be decided today, what is important I think is to widen our practices and digital presence and invite more collectives to support the cause' (Participant A, Open Assembly, September 2013).

Another one added:

'We can incorporate our activities and embed them into other socio-cultural events that are taking place currently in Athens. We can explain how these people in power who do not care about culture and the creative industries in our country are the same ones who are selling off Greek public assets...and along 
with them are auctioning creative potential...we also need a petition to gather and demonstrate public support, vote for it in the local council meetings and so on' (Participant B, Open Assembly, September 2013).

As the meeting progressed the group started concluding:

'We can re-possess the building; this is an occupation and we have to all agree that we all have passion for this thing we are doing, for what we are looking at right now, opposite us; who was going to Embros? All of us...we are Embros. Entering the building is not an issue, we all have to be accountable for it and willing to resist... shall we continue the Assembly inside the building?' (Participant C, Open Assembly, September 2013).

Eventually, residents, activists and artists reclaimed Embros once again as an independent, free public place. They decided through consensus decision making of the Assembly to re-occupy the building. Participant D noted:

'We have to be really determined now, since the building can be re-invaded and guarded by the HRDF. We have to inhabit this place and commit to that... Let us publish an open call right now online to invite everyone who cares for Embros to come and join us in re-claiming it. Lets now intensify our practices, lets all think about events that will expand the activities of Embros, lets use this opportunity to establish our collective action' (Open Assembly, September 2013).

After that, cultural and social events started running again under the direction of the local residents and artists. Diverse assemblages are moving in and out of the physical space of Embros and revise theirs' and others' misconceived assumptions about the lived-reality, about the way things are; their self-organized production of cultural events and the rhizomatic constitution of social relationships have now established Embros and constantly transform it; this demonstrates that such an urban social event can destabilize and open up new creative entanglements materialized by sustained movement of subjectivities through the permeable, relative permanence of the Embros frontlines.

The public coalesced and dispersed, dissolved and worked their way through networks and connections co-constituting Embros. By being able to fill the void of an abandoned social cultural place, participants experience the potentialities of collective 
action and its power to enact new collaborative arrangements. Their participation is shared with other local (and international) communities enabling new assembling processes to emerge, processes that give rise to new entanglements with potentially transformative capacities. One such process includes the soup kitchens organized occasionally by local residents in the physical space of Embros, along with artists groups participating in diverse assembling processes to enact this social solidarity initiatives (Minutes of Open Assembly, October, 2012).

Similarly, 'people from the 'Group of Exchangers' Bazaar of books, goods, products and services of the People's Assembly of Syntagma Square' proposed Embros' involvement in their bazaar 'New Year's Eve in Syntagma Square' (Minutes of Open Assembly, September 2012). Another assembling included a student group, Das Arts from Amsterdam that came to Embros in the spring of 2012 for a two-week workshop ('Contextual'). The organizer of the workshop explains:

'We wanted to create a new meeting space for the entire Athens art scene, focusing on contemporary performing arts. But the invitation was wider: to other social entities, such as the people living in the neighborhood of the theater, for example. We wanted to create a place where people could share their practices - be they artistic or not - give and receive feedback, discuss problems and share solutions...People were creating a new reality that wasn't there before; an open potential...The Embros Theater staged a twelve-day festival with residencies, performances, panels, discussions. The theme was 'alternative modes of production' - in terms of artistic production, social production, production of thought, discourse, imagination, possibilities and vision' (Tsipos 2012).

Interestingly, the independent group Residents of Psirri invited the Stalker and Primaveraromana collectives to give a lecture on: 'Primaveraromana, Common Actions For Social Change'. They explained their participative methodology for urban research, a process that brings space into being by constructing a "collective imaginary'. Through moving across indeterminate or void spaces of the city, communities 'actuate territories'. Referring to their moving practice as 'transurbance', 
the collective encouraged mapping city transformations through sharing and collaborative storytelling (Observation notes, Embros, 2012). For Embros, this experience of trans-urbance, a condition of entangled mobilities, opens up possibilities for (re) assembling with still unknown agents, binding diverse communities together towards creative engagement and collective action.

Embedded within a body of work that aims to challenge through capturing the dynamic quality of intertwined flows/blockages of bodies/information, actors (human and nonhuman), Embros embodies a dis-continual assembling and re-assembling of territories, that co-constitute a Badiouian event $(2005 ; 2012)$. This event is something new, beyond the individual(s) and the urban topology, and albeit for an instant, mobilizes the trans-formation of new relations between communities and their local environment. Through these temporary engagements in the site of Embros, the event becomes a temporary territorialization that does not lead to stable and bounded formations but to dis-continual, unbounded and fluid organizing interrupted by temporary breaks of relative fixity (a workshop, for example). It is situated in some very interesting and complex nodes of social movements' activity in the area including: independent media and technology initiatives, artists and cultural projects, academics, migrant rights organizations, self-organized communities. Sitting at this intersection of several pre-trans-modal projects (mobilizations, maps, discourses, stories, artwork, texts, websites, ideas), it co-constitutes emerging forms of organizing with potential for public activism and transformative collaborative engagement.

Embros represents an urban event that explores the Commons (Hardt and Negri 2011), a territory that a group of locals decided to occupy in order to inhabit an 
abandoned public building. Opening the initiative to public dialogue and participation, open assemblies are regularly organized and attended by diverse individuals and social movements who contribute and share experiences from other assemblages, from other collaborative engagements, form alter-movements (Observations of Open Assembly meetings). This collective effort can lead to the emergence of entrepreneurial initiatives that can break into institutional structures demanding some kind of social transformation.

In this respect, Embros is an alternative against increasing pressures of privatization and control of the governments over public assets of communities. It is their mobile and temporary enactment that offers them this potential and positions them as sitespecific urban assemblages; that is, through creative trans-actions with urban artifacts and other formal or informal communities, they inhabit organizational vacuoles as well as embodying new modes of social relating. Their organizing principles are meta-disciplinary initiatives that trans-form urban places through experimentation instead of representation, dynamic multiplicity instead of arboreal ordering (Deleuze and Guattari 1987).

We thus look for multiple, nomadic and subversive encounters in urban voids as we consider them productive for emergent and transformative relations of organizing. Through that we challenge the global homogeneity discourse and the global city paradigm focusing attention on heterogeneities and multiplicities, which result in sitespecific urban happenings that open up new modes of organizing and fields for creative engagement. Table 1 below summarizes the organizing properties at Embros and how temporary territories of creative engagement jointly institute mobilities 
necessary for the performance of transvergent organizing.

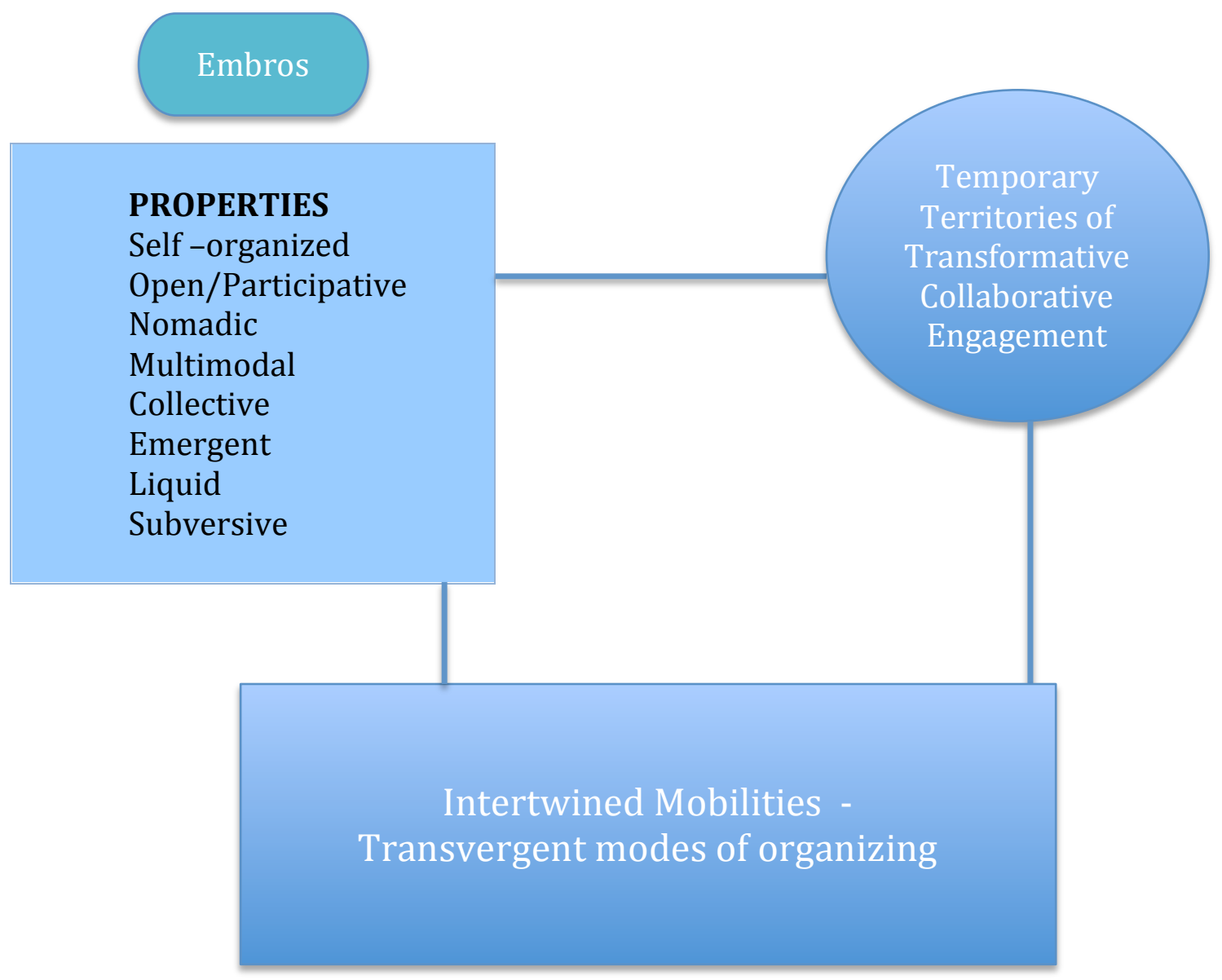

Table 1: Embros as a Transvergent Territory of Organizing

Crucial for the evolution of Embros were the periods that were declared 'Without rent, free of charge'. These constitute transformative milestones in relation to the events' values, organization and practice. Indicatively, the Mavili Collective states:

'We are excluding all kinds of financial exchange. This is because we are in search of a new organizing model -this is not just a new art-cultural space; our aim is the collective production of a community of 
social co-production and sharing that reflects transformative inter-relations that characterize contemporary cultures' (Mavili Collective, http://mavilipress.blogspot.gr).

Similar initiatives ${ }^{3}$ include the old Cinema Palazzo, an occupied building in the San Lorenzo area of Rome that has been renamed Sala Vittorio Arrigoni. In 2011, activists took over the historical theatre, which was about to be converted into casino. Since then, backed by famous artists and actors Sala Vittorio Arrigoni held a variety of cultural activities. Another significant event refers to Teatro Valle, an 18th century theatre at the heart of Rome, was taken by a group of artists (now called Teatro Valle Occupato). After a period of free or donations-based plays, movies, poetry readings, concerts and workshops, they are now thinking about alternatives both in terms of activities as well as organization.

Alternatives arising from Embros and other similar social/artists collectives are events that embody the multiple and reflect difference temporally as well as spatially. The performance of these alter-subjectivities describes a continual process of transformation-with-the-other that is not limited to neither convergence nor divergence discourses of organizing. Instead, social urban events are 'mobility pioneers' (Kesselring and Vogl 2008) - agents able to move without clear direction and visible destination - who first, embody the multiple and reflect difference temporally as well as spatially and second, constitute organizing as a transient place where spontaneous events dis-order socio-spatialities. Mobility pioneers are capable of transvergence, a constant process of emplacement, one that creates temporary experiences of in-betweeness, a feeling of simultaneous departure and arrival, of an

\footnotetext{
${ }^{3}$ See also, Alexandria, Egypt where artists and intellectuals have started their sit-in at the state-run Beram ElTonsy theatre in June 2013; The Curry Vavart collective in Paris established in 2004. It transforms abandoned buildings into performance spaces, workshops, co-operative kitchens and shared allotments. Also, more than thirty social centres in Madrid are occupying entire buildings, organizing concerts, theatre shows or plan demonstrations (e.g. Casablanca, Patio Maravilas, Kairos).
} 
immanent and eminent transformation; a trans-subjectivity that enacts and performs liminal events, like the one we discuss here.

Events of liminality ${ }^{4}$ (Van Gennep, 1960; Turner, 1969), like Embros, provide the time/space to experience the loss of the old before embracing the new; a quality that largely depends upon the capacity to envisage what comes next (Van Gennep, 1960). This capacity to visualize a possible future is an invitation to consider the precarious state of being in-between or in limbo (Mayrhofer and Iellatchitch, 2005; Ibarra, 2005; Beech, 2010). This state denotes the 'blurriness of transformation and the acute consciousness of status on either side of it' (Cohen, 1994:127). Transformation relations in liminal contexts presuppose transvergent conditions that instantiate structures of possibility: continuous emergence of entirely new fields, expanding to include the other, a continuous emergence that remains secured by facilitating ephemeral and fluid forms of organizing, modes that embrace mobility as their guiding principle:

"[Embros $]$ is not a proposition of a "better" model of production and management but is a proposition of re-thinking, responding and re-making. This model emerges from the current lacks and shortfalls of our system and attempts to interrogate the global changing landscape at this moment in time. We challenge our own limits and understanding and we propose and operate this space as a constantly reevaluated model by both ourselves and the public - an open system that might offer the potential to rethink relations between people and possible roles for art in society... Mavili Collective is committed to producing nomadic, autonomous collective cultural zones that appear and disappear beyond the logics of the market' (O'Reilly 2011).

Experiences of mobility are related to changing elements of experience - a transformation in both material and social terms: through a mobile body of agents who inhabit space before they adjourn only to reform again as different groups in another place within the city in the future. These processes of re-assembling constitute 'happenings' (Kaprow 1959) that are not attached to a specific space rather they

\footnotetext{
${ }^{4}$ From limen, Latin word for threshold (Turner, 1969).
} 
emerge through movement and collaborative engagements with other actors, activities or spaces. Space thus is not considered a container, a Euclidean fixed space, but a socio-spatial dialectic (Soja 1996) that mobilizes geographical imagination towards more heterogeneous places produced via creative engagement.

Consequently, our mobilities describe a passage from de-territorialization to reterritorialization that is actually evidence of the importance of both moorings and mobilities, a process that allows for meaningful encounters that create engaging places; 'it is the dialectics of mobility/moorings that produces social complexity' (Urry 2003, 126) and, as we will explain in the following section, transvergent social interactions during urban social practices. Embros takes place in the vacuoles of the organised, social and political realm co-constituting transvergent collectivities. These transvergent collectivities as multiple, liquid, open and multimodal assemblages in motion have the potential of moving from trans- to allo-, the Other, enacting temporary yet transformative assembling of trans-subjectivities.

\section{Discussion}

While mobile urban practices assemble temporary, emergent, fluid and mobile encounters, they constantly transform their membership, subjectivities and urban practice. And because of this, they cannot be studied as bounded organizations or networks but as 'a point of exile' (Badiou 2000, 84), territories the fragility of which, produces immanent patterns of becoming (DeLanda 2006). The fixed and the rigid become liquid, as they attain a different materiality one which is constituted by movement. Movement of assemblages (artists, residents, activists, audiences, visitors) is responsible for temporarily constituting a new territory that has unexpected 
qualities. The potential of this urban social event therefore to enact multiplicitous encounters invites dis-continual epistemology of embodied de-territorializing and reterritorializing. The networked relationships are a crucial feature creating new systems of interaction, feedback loops and mediated settings for social interaction.

Differential embedding of the assemblages' activities (even its deployment in this very paper) co-constitutes innovative points of contact and exchange among seemingly diverse and heterogeneous communities which, instead of leading to a synthesis, initiate possibilities for future engagements, a chain of subsequent entanglements. During such social urban events, there is a dis-continual process of assembling that expands these communities and their territories to include liquid transformative collaborations that may lead to transvergent organizational forms. Table 2 below outlines the properties of transvergent organizational forms and, borrowing from Novak's artistic work, visually represents these forms. 


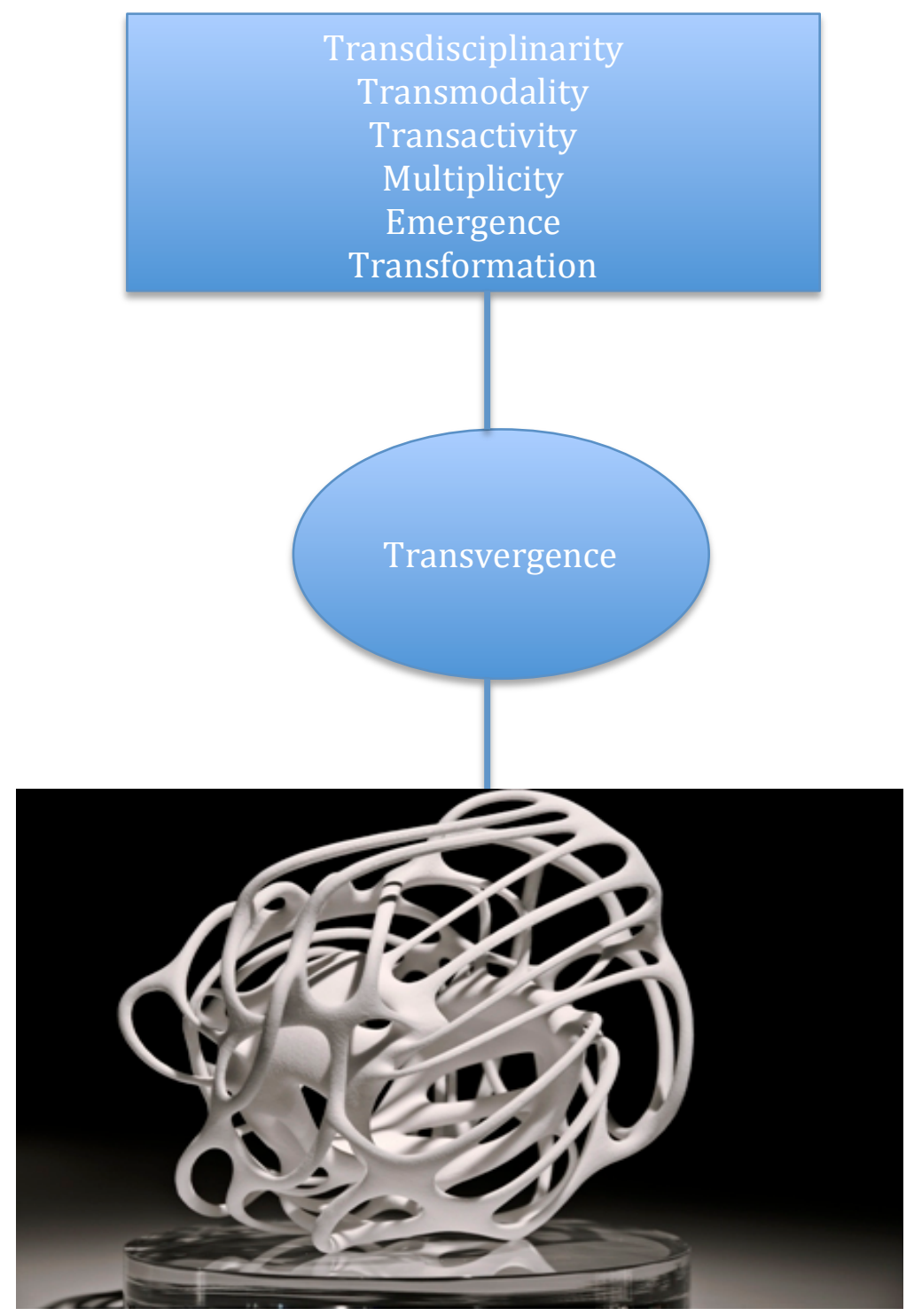

Table 2: Making the Invisible Visible. Adapted from Transarchitectures (Marcos Novak, 2002). Google Images, accessed $9^{\text {th }}$ of July 2011.

Hence Embros' assembling is: a) distributed in a differential way for different social groups and urban communities and b) results to specific territorial configurations. These configurations or mobility patterns become possible through temporary emplacements and multiple belongings. The experience of multiple and intertwined mobilities becomes very important as the driving force behind a transformative reassembling process. This is because simultaneous participation in diverse sociocultural and political communities and temporary entanglement with fluid multiplicities and singularities is what makes transvergent territories visible and what 
creates new organizational potentialities. These organizational potentialities would signify exodus and invention; in particular, both convergence and divergence approaches/disciplines are restrictive paradigms if transformation in social relations is sought out. Instead transvergent forms entail autonomous, open/participative, nomadic, multimodal, collective, emergent and performative liminal spaces where innovative practices assemble formal or informal communities and more importantly re-organize socio-spatial relations for a cultural foundation that gives place back to the public. Table 3 below summarizes these inter-relationships that link mobility and transvergence through a process of assembling and re-assembling relations.

Transvergent formations are thus embedded not in one but in multiple assembling processes; some of these come together in a concrete urban void, like the Embros site. However, for this 'void' to remain transvergent, it has to remain open to flows of people, difference and new assemblages that may emerge during the process. Reassembling indicates a cycle of de/re-territorialization in a given urban space. Mobile socio-spatial relations constantly transform space into a liminal, 'in-between place' that reinforces creative engagement, artistic improvisation, emergence of new assemblages and practice breakthroughs. 


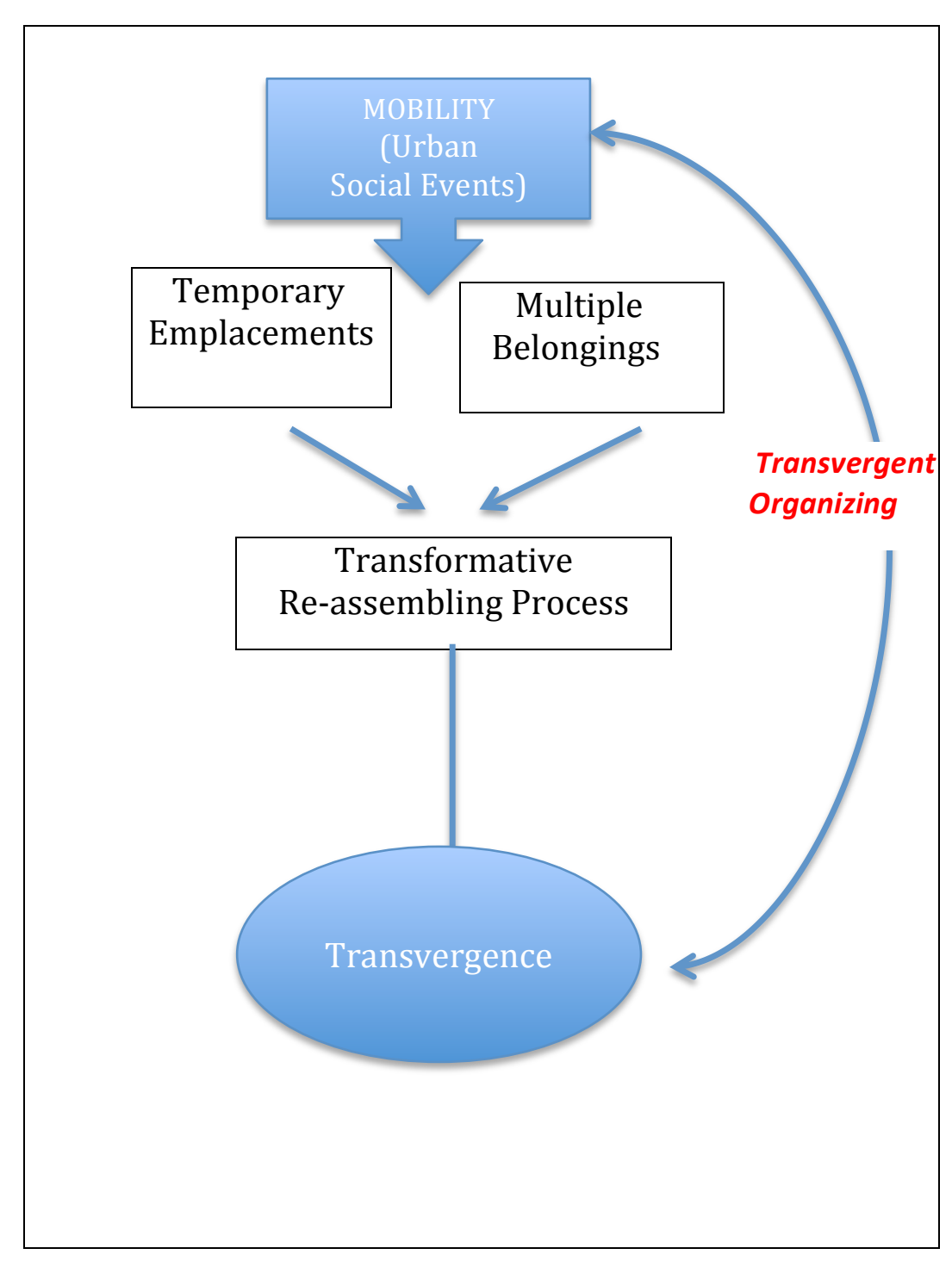

Table 3: Mobility and Transvergent Organizing

\section{Concluding Remarks}

In this paper, we examined the possibility that something substantial can be made from things that are invisible or hardly visible. Similarly to Derrida's quest which seeks to examine what lies beyond sight, we want to describe the 'ghosts' of organization studies, void spaces or moments of border-crossing: 'To see sight or vision or visibility, to see beyond what is visible, is not merely "to have a vision" in the usual sense of the word, but to see beyond-sight, to see-sight-beyond-sight' (Derrida 2004, 75). We looked for living cities within these voids, seek for urban encounters that are 'meetings, or collisions between two [or more] fields of force, 
transitory but ultimately transformative...moments of production' (O’Sullivan 2006, 21). These encounters we proposed, invite transvergent forms of organizing which also mirror conditions of flux, unpredictability and liminality. The latter, a concept largely overlooked in the field of organization studies, can be further explored in future studies particularly with regard to territorial organization of urban social events and socio-spatial assembling processes.

Indeed, urban social events as places of inherent mobility can enrich our understanding of organizing and interrelating in increasingly liminal environments. We proposed another way to theorize relationships in these environments encouraging approaches that account for unbounded and ephemeral assembling. We did not counter-argue modernist and postmodernist considerations on assemblage (Deleuze, DeLanda, Latour); we only shifted the focus towards temporary and mobile assembling in order to capture the complex process of assemblage transformation. This cyclical de/re-territorialization process is achieved not only due to the inherent mobility of these permeable assemblages but also due to the performative aspects of assembling.

Accordingly, we encourage future work on these performative aspects that is, what it does and how it functions across space and time, rather than what it means. Performative assembling here refers largely to the political potential that such creative encounters instantiate by opening up new lines of communication and participation. They purport a certain creative and affective modality established upon the desire for emancipation and self-determination enabled by active participation and reciprocal communication. We suggest that future work could depart from what is commonly 
understood as a typical political platform: If what is required is 'a politics of belonging instead of a politics of identity, of correlated emergence instead of separate domains of interest attracting each other or colliding in predictable ways [...] a pragmatic politics of the in-between' (Massumi 2002, 223), then it is clear how the study of performative assembling could help contribute to such a politics.

We proposed that social urban events are temporary territories, which create opportunities for spatial and social transvergence. Multitudes (human and nonhuman) are moving in space and temporarily occupy transvergent territories and trans-identities. Due to their liminal condition, they achieve temporary emplacements and multiple belongings and in effect, trans-form practice and constitutes them as novel sites of collaboration: through creative interactions with the urban landscape and formation of temporary assemblages within urban communities, they inhabit voids and transform the routes and modes of established social relations.

'Places, bodies, face-to-face networks, social histories, and the messiness of offline politics continue to matter, as exemplified by the resonance of the physical occupations themselves' (Juris 2012, 260). Although the paper made no direct reference to this, it is clear, however, that new media influence how urban social events in general, organize and evolve. 'Spatially dispersed yet coordinated, fluid collections of wirelessly interconnecting individuals - perhaps assembled, from the beginning, in cyberspace rather than at any physical location - are becoming a crucial fact of urban life' (Mitchell 2003, 161). Technologies of both very hard, material quality as well as the virtual layers of these are being inserted into urban sites creating new opportunities for re-thinking relationships between flows and fixity, local and 
global, and human agency and technological artifacts. Distributed virtual-corporeal assemblages provide new dimensions towards a different configuration, circulation and activation of organizational spaces - interacting subjectivities that are transformed, signifying links with a more technological ontological condition.

Rather than reproducing an established dichotomy between the material and the virtual, we propose that the intra-related subjectivities of virtual-physical entanglements are a crucial feature in creating new systems of interaction, feedback loops and mediated settings for social interaction. This is a really important issue that future work could explore further when focusing on entangled (virtual) mobilities and the organization of transvergent environments. Yet, recognizing the different processes involved in a virtual-corporeal assembling, we propose that future studies can also reflect upon the different territories that emerge due to the qualitatively different territorial configurations of virtual and/or corporeal assembling.

Through the discussion of Embros, we made visible the immanent potentialities of urban social events and discussed them as places of engagement and social transformation. Heterogeneity and dis-ordering strategies result in distinctive patterns of mobility-immobility that characterize (con-) temporary communities and the social events that they constitute. They are rhizomatic formations which allow assemblages to remain fluid, organic, a-centered and able to form linkages (canals) with other social formations or new assemblages and in the future, new transformative events. Hence, involvement with the unexpected and the unpredictable constitutes places of dialogical performance that allow participants to challenge pre-existing bounded 
identities and the power relations that they entail, constructing new creative practice territories (Daskalaki and Mould 2013).

To conclude, by focusing on territories of creative engagement, we discussed mobility in relation to the urban assemblages that co-constitute what we called, social urban events, self-organized territories of creative collaborative engagement. Conversing predominantly with an urban studies discourse, we illustrated how mobility constitutes creative collaborations that do not result in bounded subcultural phenomena but to new constellations which constantly expand to include the other (the different, the invisible, the outsider). Urban social events, enabled by conditions of mobility, constitute platforms for organizing emergent social relations, whose constant re-configuring between agents, structures, practices, discourses and sociotechnical systems introduces what could become a transvergent theory of organizing. 


\section{References}

Adey, Peter, and Paul Bevan. 2004. “Connected Mobility?”. Paper prepared for Alternative Mobilities Conference: held at Lancaster University, January

Amin, Ash, and Nigel, Thrift. 2002. Cities: Reimagining the Urban. Cambridge: Polity.

Augé, Marc. 1995. Non-places: Introduction to an anthropology of supermodernity. London: Verso.

Badiou, Alain. 2000. Deleuze: The Clamor of Being. Minneapolis and London: University of Minnesota Press.

Badiou, Alain. 2005. Being and Event. London: Continuum.

Badiou, Alain. 2012. The Rebirth of History: Times of Riots and Uprisings. London: Verso.

Barad, Karen. 2001. "Re(con)figuring Space, Time, and Matter". In Feminist Locations: Global and Local, Theory and Practice, ed. Marianne DeKoven, 75-109. New Brunswick, N.J.: Rutgers University Press.

Barad, Karen. 2007. Meeting the Universe Half Way: Quantum Physics and the Entanglement of Matter and Meaning. Durham: Duke University Press.

Bloch, Ernst. 1986. The Principle of Hope. MIT Press.

Borden, Iain. 2001. Skateboarding, Space and the City: Architecture and the Body. Oxford: Berg.

Beach, Nic. 2011. Liminality and the practices of identity reconstruction. Human Relations, 64 (2): 285-302.

Cohen, Robin. 1994. Frontiers of identity: The British and the Others, Longman sociology series. London: Longman.

Cresswell, Tim. 2006. On the Move. Mobility in the Modern Western World. London: Routledge.

DeLanda, Manuel 2006. A New Philosophy of Society. London: Continuum.

Daskalaki Maria, Alexandra Stara and Miguel Imas. 2008. "The 'Parkour Organisation': Inhabitation of Corporate Spaces”. Culture and Organization 14, 1: 49 $-64$

Daskalaki, Maria, and Oli Mould. 2013. "Beyond Urban Subcultures: Urban Subversions as Rhizomatic Social Formations." International Journal of Urban and Regional Research. 37(1): 1-18. 
Derrida, Jacques. 2004. (1979) 'Living on' In Deconstruction and Criticism. Harold Bloom, Paul de Man, Jacques Derrida, Geoffrey H. Hartman, J. Hillis Miller, (Eds), pp. 62- 142. London and New York: Continuum.

Doel, Marcus. 1999. Poststructuralist Geographies: The Diabolical Art of Spatial Science. Rowman and Littlefield, Lanham.

Deleuze, Giles, and Felix Guattari. 1987. A Thousand Plateaus: Capitalism and Schizophrenia. Minneapolis, MN: University of Minnesota Press.

Garrett, Bradley. 2010. 'Urban Explorers: Quests for Myth, Mystery and Meaning'. Geography Compass, 4 (6): 1448-1461.

Gibson-Graham, Julie Kathy. 1997. "Postmodern Becomings: From the Space of Form to the Space of Potentiality". In Space and Social Theory: Interpreting Modernity and Postmodernity, edited by Georges Benko and Ulf Strohmayer, 306323. Oxford: Blackwell Publishers.

Gupta, Vipin and Jifu Wang. 2004. "The Transvergence Proposition Under Globalization: Looking Beyond Convergence, Divergence and Crossvergence". Multinational Business Review, 12 (2): 37-57.

Harvey, David. 1989. The Urban Experience. The Johns Hopkins University Press.

Harvey, David. 2009. Cosmopolitanism and the Geographies of Freedom New York: Columbia University Press.

Hardt, Michael, and Antonio Negri. 2011. Commonwealth. Cambridge: Belknap.

Jensen, Ole. 2006. "Facework, Flow and the City. Simmel, Goffman and Mobility in the Contemporary City". Mobilities 2 (2): 143-165

Jensen, Ole. 2009 "Flows of Meaning, Cultures of Movements - Urban Mobility as Meaningful Everyday Life Practice”. Mobilities 4 (1): 139-158.

Juris, Jeffrey. 2012. "Reflections on \#Occupy Everywhere: Social media, public space, and emerging logics of aggregation”, American Ethnologist, 39 (2): 259-279.

Ibarra, Herminia. 2005. Identity transitions: Possible selves, liminality and the dynamics of career change. Working Paper Series, INSEAD, 2005/51/OB

Kaprow, Alan. 1959. 18 Happenings in 6 Parts. Germany: Seidi Hauser \& Wirth.

Kesselring, Sven, and Gerlinde, Vogl. (2008). "Networks, Scapes and Flows Mobility Pioneers between First and Second Modernity", in Tracing Mobilities: Towards a cosmopolitan perspective in mobility research, edited by Canzler, Weert, Vincent Kaufmann, Sven Kesselring, 163 - 180. Aldershot, Burlington: Ashgate.

Latour, Bruno. 2005. Reassembling the Social: An Introduction to Actor-NetworkTheory. Oxford: Oxford University Press. 
Mar, Phillip, and Kay, Anderson. 2012. "Urban Curating: The "Interspaces" of Art

Collaboration in Western Sydney". Space and Culture, 15(4): 1-14

Massey, Doreen. 2005. For Space. London: Sage.

Massey, Doreen. 2007. World City. Cambridge: Polity Press.

Massumi, Brian. 2002. "Navigating moments". In Hope: New Philosophies for

Change, ed. M. Zournazi, 210-244. New York: Routledge.

Mavili Collective, http://mavilipress.blogspot.gr, accessed in June 2012

Mould, Oli. 2009. 'Parkour, the City, the Event'. Environment and Planning D: Society and Space 27(4): 738 - 750.

Mitchell, D. 1995. "The End of Public Space? People's Park, Definitions of the Public and Democracy". Annals of the Association of American Geographers, 85 (1): 108 133.

Murdoch, Jonathan. 2006. Post-Structuralist Geography. London: Sage.

Novak, Marcos. 1992. Liquid Architectures of Cyberspace, Cyberspace: First Steps, edited by Michael Benedikt. Cambridge, MA: The MIT Press 31-47.

Novak, Marcos 1999. Avatarchitectures: Fashioning Vishnu after Spacetime, From Energy to Information, Stanford University Press, Palo Alto, California.

Novak, Marcos. 2001. Marcos Novak Interview. Interview by Alessandro Ludovico. http://www.neural.it/english/marcosnovak.htm, accessed 10/1/2004.

Novak, Marcos. 2002. "Speciation, Transvergence, Allogenesis Notes on the Production of the Alien", in Reflexive Architecture, edited by Spiller N., 64-71. London: Wiley Academy.

Novak, Marcos. 2004. Interview with M. Novak. The World Technology Network, http://www.wtn.net/2004/bio212.html, accessed in February 2012.

O'Reilly, Katherine. 2011. "Occupation as cultural intervention: The Mavili Collective".

http://kaiteoreilly.wordpress.com/2011/11/11/occupation-as-cultural-intervention-themavili-collective/), accessed in April 2012.

O'Sullivan, Simon. 2006. Art Encounters Deleuze and Guattari: Thought Beyond Representation, London: Palgrave.

Lassen, Claus. 2006. "Work and Aeromobility", Environment and Planning A 38(2): 301-312.

Law, John. 2006. "Disaster in Agriculture, or Foot and Mouth Mobilities", 
Environment and Planning A, 38: 227-239.

Marcus, GE, and Saka E. 2006. Assemblage. Theory, Culture and Society 23 (2-3): 101-109.

Mayrhofer, Wolfgang. and Alexandre Iellatchitch. 2005. Rites, right? The value of rites de passage for dealing with today's career transitions. Career Development International, 10 (1), 52-66.

McCann, Eugene. 2011. 'Urban policy mobilities and global circuits of knowledge: Toward a Research Agenda'. Annals of the Association of American Geographers 101 (1): 107- 130 .

McFarlane, Colin. 2011. 'Cosmopolitanism's Geographies: A Review of David Harvey's Cosmopolitanism and the Geographies of Freedom. Review Essay for Symposium'. Dialogues in Human Geography 1 (1): 107-110.

Residents and Workers of Psirri, http://psyrri.blogspot.gr, accessed in January 2013.

Ruppert, E. 2006. "Rights to Public Space: Regulatory Reconfigurations of Liberty", Urban Geography, 27(3): 271-292.

Saville, Stephen. 2008. "Playing with Fear: Parkour and the mobility of emotion". Social and Cultural Geography 9(8): 891 - 914.

Sassen, Saskia. 2006. Territory, Authority, Rights: From Medieval to Global Assemblages. Princeton: Princeton University Press.

Sennett, Richard. 1994. Flesh and Stone: The Body And The City In Western Civilization. Norton

Soja, Edward. 1996. Thirdspace: Journeys to Los Angeles and Other Real-andimagined Places. London, Blackwell.

Thrift, Nigel. 1996. Spatial formations. London: Sage Publications.

Thrift, Nigel. 2008. Non-representational Theory: Space, Politics, Affect. London: Routledge.

Tsipos, Michael. 2012. "Times of crisis shake and alert people" http://www.ahk.nl/theaterschool/opleidingen-theater/dasarts-master-of-theatre/blockscontextuals/spring-2012/manolis-tsipos/, accessed 30 ${ }^{\text {th }}$ of April, 2013.

Turner, Victor. 1969. The Ritual Process. London: Routledge and Kegan.

Urry, John. 2003. Global Complexity, Oxford: Polity.

Urry, John. 2008. Mobilities, Cambridge: Polity.

Van Gennep, A. 1960. Rites of Passage. Chicago, IL.: University of Chicago Press. 
Young, Iris Marion. 1990. Justice and the politics of difference. Princeton: Princeton University Press.

Weintraub, Jeff. 1995. 'Varieties and Vicissitudes of Public Space'. In Metropolis: Center and Symbol of our Times, ed. P. Kasinitz. New York: New York University Press. 